\title{
Cinética de degradação e fermentação ruminal da Brachiaria brizantha cv. marandu colhida em diferentes idades ao corte
}

\author{
[Degradation and fermentation kinetics of Brachiaria brizantha $c v$. \\ Marandu at differents cutting ages] \\ G.H.F. Castro ${ }^{1}$, D.S. Graça ${ }^{1}$, L.C. Gonçalves ${ }^{1}$, R.M. Mauricio ${ }^{2}$, N.M. Rodriguez ${ }^{1}$ \\ I. Borges ${ }^{1}$, T.R. Tomich ${ }^{3}$ \\ ${ }^{1}$ Escola de Veterinária - UFMG \\ Caixa Postal, 567 \\ 31270-901 - Belo Horizonte, MG \\ ${ }^{2}$ Fundação Ezequiel Dias - Belo Horizonte, MG \\ ${ }^{3}$ Embrapa Pantanal - Corumbá, MS
}

\begin{abstract}
RESUMO
Avaliou-se a cinética de fermentação ruminal de capim-braquiarão cortado aos $28,56,84$ e 112 dias de rebrota, mediante o uso da técnica in vitro semi-automática de produção de gases. A relação entre a digestibilidade da matéria seca e a produção acumulada de gases foi linear em todas as idades ao corte. $\mathrm{O}$ capim-braquiarão cortado aos 28 e aos 56 dias apresentou a maior taxa de produção de gases em torno das 18 horas de incubação, enquanto na forragem cortada aos 84 e 112 dias a maior taxa foi observada após 48 horas de incubação. Em todos os tempos de incubação a produção acumulada de gases foi maior na forragem cortada aos 28 e aos 56 dias. Conclui-se que o melhor momento de utilização do capimbraquiarão está entre as idades de 28 e de 56 dias, devido à maior fermentabilidade ruminal da forrageira cortada nessas idades.
\end{abstract}

Palavras-chave: braquiária, produção de gases, valor nutritivo

\begin{abstract}
Fermentation kinetics of Brachiaria brizantha $c v$ Marandu harvested on 28, 56, 84, and 112 days of growth was evaluated with the semi-automatic in vitro gas production technique. Regression equations between volume of gas and dry-matter digestibility during fermentation periods of treatments were linear. Marandu grass harvested on 28 and 56 days of growth showed the greatest rate of gas production around 18 hours of incubation, while the rate of gas production of forages cut at 84 and 112 days reached the peak at 36 hours of incubation. Cumulative gas production was higher on 28 and 56 days of harvest intervals than grass harvested on 84 and 112 days. Therefore, the best harvest stage for using Brachiaria brizantha $c v$ Marandu were between 28 and 56 days due to highest ruminal fermentability.
\end{abstract}

Keywords: grass, gas production, nutritive value

\section{INTRODUÇ̃̃O}

Cerca de $50 \%$ das pastagens estabelecidas no Brasil são formadas por gramíneas do gênero Brachiaria. Dentre as espécies e cultivares deste gênero, destaca-se o capim-braquiarão (Brachiaria brizantha cv Marandu; Zimmer et al., 1995). Esse cultivar tem boa adaptação aos

Recebido em 7 de julho de 2006

Aceito em 25 de setembro de 2007

E-mail: ghfcastro@ufmg.br solos do cerrado, responde bem à adubação fosfatada e tem boa tolerância à cigarrinha das pastagens (Nunes et al., 1985).

A produção de matéria seca desta forrageira varia de 0,3 até 13,5 ton/ha, conforme a idade ao corte, de 14 até 126 dias (Nunes et al., 1985; Borges et al., 2002). Com relação à composição químico-bromatológica, são descritos para o 
capim-braquiarão valores de proteína bruta de $8,9 \%$ a $18,6 \%$, de fibra em detergente neutro de $57,9 \%$ a $72,7 \%$ e digestibilidade in vitro da matéria seca de $59,4 \%$ a $71,6 \%$, os quais também são influenciados pela idade da planta ao corte (Ferrari Júnior et al., 1994; Soares Filho et al., 2002).

Como toda forrageira tropical, esta gramínea concentra a maior parte de sua produção de matéria seca durante o período das chuvas, principalmente em conseqüência de fatores climáticos, como temperatura e precipitação pluviométrica (Van Soest, 1994). Desse modo, em certas situações, adota-se a prática de conservar parte da produção de forragem do verão, para ser utilizada no inverno, com o intuito de manter uniforme a disponibilidade de volumoso para a alimentação animal durante todo o ano. Para isso, deve-se determinar a melhor idade ao corte ou de pastejo da forragem. Esta idade deve representar o ponto de equilíbrio entre o valor nutritivo e a produção de matéria seca, (PMS), pois nas forrageiras a PMS aumenta, e o valor nutritivo diminui à medida que aumenta a idade ao corte (Van Soest, 1994; Corrêa e Pott, 2001).

Metodologias in vitro de avaliação de alimentos têm sido utilizadas para a determinação do valor nutricional de forrageiras, registrando-se alta correlação entre o consumo e a digestibilidade in vivo (Ørskov, 2002). Segundo Wiliams (2003), as técnicas in vitro de produção de gases têm sido utilizadas em estudos de classificação de substratos com altos teores de carboidratos, em estudos de fermentabilidade de componentes específicos, na avaliação de fatores antinutricionais e na predição da energia metabolizável dos alimentos.

O presente estudo teve como objetivo avaliar a digestibilidade in vitro da matéria seca $\mathrm{e}$ descrever a cinética de fermentação ruminal do capim-braquiarão cortado em quatro idades utilizando-se a técnica in vitro semi-automática de produção de gases.

\section{MATERIAL E MÉTODOS}

O capim-braquiarão foi cultivado em um solo com as seguintes características: $\mathrm{pH}$ 6,1; alumínio $4 \mathrm{mmol}_{\mathrm{c}} / \mathrm{dm}^{3}$; cálcio $13 \mathrm{mmol}_{\mathrm{c}} / \mathrm{dm}^{3}$; magnésio $6 \mathrm{mmol}_{\mathrm{c}} / \mathrm{dm}^{3}$; fósforo $2 \mathrm{mg} / \mathrm{dm}^{3}$ e potássio $97 \mathrm{mg} / \mathrm{dm}^{3}$. $\mathrm{Na}$ área onde foram estabelecidos os canteiros, foi executada calagem com 1,4t/ha de calcário dolomítico e foi feita adubação com $330 \mathrm{~kg}$ de sulfato de amônio, $100 \mathrm{~kg}$ de cloreto de potássio e $333 \mathrm{~kg}$ de superfosfato simples de acordo com a análise de solo. Quatro canteiros, medindo $8 \times 8 \mathrm{~m}$, foram distribuídos aleatoriamente por tratamento. A forrageira foi cortada nas idades de 28, 56, $84 \mathrm{e}$ 112 dias. As amostras foram obtidas pelo corte da área central $(2 \times 2 \mathrm{~m})$ de cada canteiro, à altura de $20 \mathrm{~cm}$ do solo. Essas amostras foram présecadas a $60^{\circ} \mathrm{C}$ por 48 horas em estufa de ventilação forçada, e combinadas em um composto homogêneo de todos os canteiros de cada tratamento.

As amostras foram moídas em moinho com peneira com crivos de um milimetro e um grama foi adicionado ao frasco de fermentação com capacidade de $160 \mathrm{ml}$, que havia sido previamente injetado com gás carbônico $\left(\mathrm{CO}_{2}\right)$. Posteriormente, foi adicionado $90 \mathrm{ml}$ de meio de cultura. Esse era composto de 71 de soluçãotampão (carbonato de amônio e bicarbonato de sódio); 71 de solução macromineral (fosfato de sódio, fosfato de potássio e sulfato de magnésio); $3,5 \mathrm{ml}$ de solução micromineral (cloreto de cálcio, cloreto de manganês, cloreto de cobalto, cloreto ferroso); $35,2 \mathrm{ml}$ de solução de rezazurina $0,1 \%$ e meio B (cisteína, hidróxido de sódio $1 \mathrm{~m}$ e sulfito de sódio), conforme recomendação de Maurício et al. (1999). Os frascos foram então mantidos sob refrigeração $\left(4^{\circ} \mathrm{C}\right)$ até cinco horas antecedentes à inoculação e, posteriormente, transferidos para a estufa a $39^{\circ} \mathrm{C}$, onde permaneceram por aproximadamente $8 \mathrm{~h}$.

O inóculo ruminal foi retirado de dois bovinos com cânula ruminal, alimentados com $1,5 \mathrm{~kg} / \mathrm{dia}$ de concentrado comercial com $16 \%$ de proteína bruta e capim-elefante (Pennisetum purpureum) picado à vontade. Estes animais foram adaptados à dieta durante 14 dias. Retirou-se em torno de dois litros de inóculo ruminal que foram armazenados seperadamente em garrafas térmicas previamente aquecidas a $39^{\circ} \mathrm{C}$. Este era composto por $3 / 4$ da fase líquida e $1 / 4$ da fase sólida do contéudo ruminal. Antes da inoculação, o inóculo foi filtrado, utilizando-se somente o líquido ruminal. Avaliação quanto às características físico-químicas e atividade microbiana dos líquidos ruminais são apresentadas na Tab. 1. 
Tabela 1. Características do líquido ruminal dos dois bovinos utilizados no estudo in vitro

\begin{tabular}{|c|c|c|}
\hline Avaliação & $\begin{array}{l}\text { Líquido ruminal do } \\
\text { bovino } 1\end{array}$ & $\begin{array}{l}\text { Líquido ruminal do } \\
\text { bovino } 2\end{array}$ \\
\hline $\operatorname{Cor}^{1}$ & Oliva & Oliva \\
\hline Odor $^{1}$ & Aromático forte & Aromático forte \\
\hline Viscosidade $^{1}$ & Ligeiramente viscoso & Ligeiramente viscoso \\
\hline $\mathrm{pH}$ & 6,8 & 7,0 \\
\hline Tempo de redução do azul de metileno & $1 \mathrm{~min} 20 \mathrm{~s}$ & $1 \mathrm{~min} 30 \mathrm{~s}$ \\
\hline Sedimentação & $5 \mathrm{~min}$ & $5 \mathrm{~min}$ \\
\hline Atividade de protozoários ${ }^{1}$ & Moderada & Moderada \\
\hline
\end{tabular}

Classificado conforme Dirksen et al. (1993).

Para a inoculação, foram utilizados $10 \mathrm{ml}$ de líquido ruminal por frasco. Após a inoculação, foram eliminados os gases residuais presentes (tempo zero) com o auxílio de agulhas, e os frascos foram vedados e mantidos em estufa a $39^{\circ} \mathrm{C}$ por $6,12,24,48$ e $96 \mathrm{~h}$, quando foram retirados para a estimativa da digestibilidade in vitro da matéria seca (DIVMS). Foram utilizados três frascos por líquido ruminal por tempo de DIVMS por idade de corte. Frascos contendo líquido ruminal e meio de cultura foram usados como controle (branco).

A pressão de gases nos tempos de $2,4,6,8,10$, $12,15,18,21,24,30,36,48,60,72$ e 96 horas de incubação foi medida por meio de um transdutor de pressão. A transformação dos valores de pressão de gases (x) em volume de gases (VG) foi estimada pela equação $\mathrm{VG}(\mathrm{ml})$ $=-0,004+4,43 \mathrm{x}+0,051 \mathrm{x}^{2}$, descrita por Maurício et al. (2003).

A DIVMS foi estimada segundo Theodorou et al. (1994). Nos respectivos tempos, os frascos foram resfriados com água fria para interromper a fermentação, e armazenados sob refrigeração $\left(4^{\circ} \mathrm{C}\right)$, até o processo de filtragem. A DIVMS foi obtida pela filtragem do conteúdo dos frascos sob vácuo, em cadinhos de filtragem de borossilicato com porosidade 1, previamente pesados (Theodorou et al., 1994). Esses cadinhos com o resíduo de incubação foram mantidos por 48 horas em estufa a $105^{\circ} \mathrm{C}$ e pesados. De acordo com o teor de matéria seca (MS; Official..., 1980) determinado no substrato incubado de cada tratamento, foi calculada a DIVMS. O coeficiente de correlação e as equações de regressão entre a DIVMS e a produção acumulada de gases (Y) foi obtida pelo PROC CORR e PROC REG, respectivamente, do software (SAS/STAT..., 1993).

Os volumes acumulados de gases foram ajustados ao modelo proposto por France et al.
(1993) com o programa Maximun Likelihood Program (MLP), segundo Ross (1987): $\mathrm{PG}=\mathrm{A}$ $*[1-\exp (-\mathrm{c}(\mathrm{t}-\mathrm{L})-\mathrm{b}(\sqrt{\mathrm{t}}-\sqrt{\mathrm{L}}))] ; \mu=\mathrm{b}+(\mathrm{c} / 2+\sqrt{\mathrm{t}}))$, em que $\mathrm{Y}$ é a produção acumulada de gases $(\mathrm{ml})$; A é o potencial máximo de produção de gases (ml); L é o tempo de colonização das partículas (horas); b e c são as taxas fracionais constantes (horas $^{-1}$ e horas ${ }^{-0,5}$ respectivamente); $t$ é o tempo de incubação (horas) e $\mu$ é a taxa de produção de gases $\left(\right.$ horas $\left.^{-1}\right)$. A partir dessas variáveis foi calculado o valor do tempo de fermentação de $50 \%$ do substrato incubado (T/2).

No material incubado foram determinados os teores de MS, matéria orgânica (MO), cinzas e proteína bruta (PB) segundo Official... (1980), e fibra em detergente neutro (FDN), fibra em detergente ácido (FDA), hemicelulose (HCEL), celulose (CEL) e lignina (LIG), segundo Van Soest et al. (1991).

O delineamento experimental foi o de blocos ao acaso em esquema de parcelas subdivididas; tendo como fontes de variação dois líquidos ruminais (blocos), quatro idades de corte (parcelas) e cinco tempos de incubação (subparcelas). As médias dentro de cada período de incubação e entre as médias dos tempos de incubação foram comparadas pelo teste de Student Newman Keuls $(\mathrm{P}<0,05)$, com software SAS (SAS/STAT..., 1993).

\section{RESULTADOS E DISCUSSÃO}

$\mathrm{Na}$ Tab. 2, observam-se os valores da composição químico-bromatológica do capimbraquiarão nas quatro idades ao corte. Em razão da ausência de repetições, pois foram feitas amostras compostas por tratamento, os resultados de composição químico-bromatológica não foram submetidos à avaliação estatística. 
Cinética de degradação e fermentação...

Tabela 2. Composição bromatológica (em \% da MS) de Brachiaria brizantha cv. Marandu aos 28, 56, 84 e 112 dias de idade

\begin{tabular}{lcccc}
\hline Composição & 28 & 56 & 84 & 112 \\
\hline MS & 18,8 & 19,4 & 21,6 & 27,5 \\
MO & 91,9 & 89,1 & 92,9 & 92,8 \\
PB & 11,6 & 8,5 & 5,0 & 4,8 \\
FDN & 51,7 & 56,9 & 61,2 & 60,6 \\
FDA & 26,7 & 33,0 & 35,1 & 34,5 \\
HCEL & 25,1 & 24,0 & 26,1 & 26,1 \\
CEL & 22,4 & 29,9 & 29,7 & 29,1 \\
LIG & 4,5 & 4,1 & 5,5 & 5,5 \\
CINZAS & 8,01 & 11,0 & 7,1 & 7,2 \\
\hline
\end{tabular}

MS: matéria seca; MO: matéria orgânica; PB: proteína bruta; FDN: fibra em detergente neutro; FDA: fibra em detergente ácido; HCEL: hemicelulose; CEL: celulose; LIG: lignina.

O teor de MS aumentou progressivamente com o envelhecimento da gramínea. Foram obtidas concentrações muito semelhantes de MO entre as idades ao corte. Com relação à concentração de $\mathrm{PB}$, houve diminuição dos teores deste nutriente com o aumento da idade ao corte. Foram observados aumentos nos valores de FDN e FDA com o avançar da idade de corte. O maior teor de HCEL foi observado no capim-braquiarão cortado aos 84 e aos 112 dias, enquanto no corte aos 28 dias o teor observado foi menor que os dos cortes citados anteriormente, no entanto, mais alto quando comparado à forragem cortada aos 56 dias. Com relação à fração da parede celular correspondente à CEL, observou-se o menor valor no capim-braquiarão cortado aos 28 dias e a maior concentração na forragem cortada aos 56, aos 84 e aos 112 dias. A menor concentração de LIG foi observada na forragem aos 28 e aos 56 dias, com concentrações intermediárias no corte à idade de 112 dias; e maior valor na idade de 84 dias.
Os valores de MS, FDN, FDA e LIG aumentam, e os valores de PB diminuem em conseqüência da maior participação da parede celular em relação ao conteúdo celular na célula vegetal, com o avançar da idade da planta (Van Soest, 1994). Tal tendência pode ser observada no capim-braquiarão avaliado neste experimento.

$\mathrm{Na}$ Tab. 3, é apresentada a PG no capimbraquiarão cortado em quatro idades. No tempo inicial de seis horas, não se observou diferença $(\mathrm{P}>0,05)$ entre os tratamentos. A partir de 12 horas, a forragem cortada aos 38 dias produziu maior volume acumulado de gases do que aquela cortada aos 84 dias $(\mathrm{P}<0,05)$. Valores intermediários foram observados às 12 horas no capim-braquiarão aos 56 e aos 112 dias. No tempo de incubação de 24 horas $(\mathrm{P}>0,05)$ não houve diferença entre a forragem cortada aos 56 e aos 28 dias, mas estes valores foram maiores do que aqueles do capim cortado às idades de 84 e $112 \operatorname{dias}(\mathrm{P}<0,05)$.

Tabela 3. Produção acumulada de gases (ml) das gramíneas Brachiaria brizantha cv Marandu nas idades de corte aos $28,56,84$ e 112 dias

\begin{tabular}{lcccc}
\hline $\begin{array}{r}\text { Tempo } \\
\text { (horas) }\end{array}$ & 28 & \multicolumn{2}{c}{ Idade de corte (dias) } \\
\hline 6 & $27,9 \mathrm{Ae}$ & $26,6 \mathrm{Ae}$ & 84 & 112 \\
12 & $80,2 \mathrm{Ad}$ & $77,9 \mathrm{ABd}$ & $22,7 \mathrm{Ae}$ & $23,4 \mathrm{Ae}$ \\
24 & $159,5 \mathrm{Ac}$ & $156,9 \mathrm{Ac}$ & $62,2 \mathrm{Bd}$ & $62,0 \mathrm{ABd}$ \\
48 & $209,5 \mathrm{Ab}$ & $210,3 \mathrm{Ab}$ & $136,0 \mathrm{Bc}$ & $132,2 \mathrm{Bc}$ \\
96 & $237,1 \mathrm{Aa}$ & $241,3 \mathrm{Aa}$ & $197,4 \mathrm{ABb}$ & $191,8 \mathrm{Bd}$ \\
\hline
\end{tabular}

Médias seguidas de letras minúsculas distintas na coluna ou maiúsculas distintas na linha indicam diferenças entre valores $(\mathrm{P}<0,05 ; \mathrm{SNK})$. 
No tempo de 48 horas de incubação, a forragem cortada aos 28 e aos 56 dias apresentou maior PG do que aos 112 dias $(\mathrm{P}<0,05)$. No entanto, o capim-braquiarão cortado aos 84 dias produziu valores intermediários, os quais foram equivalentes estatisticamente $(\mathrm{P}>0,05)$ aos observados na forragem cortada aos 28 , aos 56 e aos 112 dias de idade. Com 96 horas de incubação, não foi observada diferença $(\mathrm{P}>0,05)$ na PG.

A principal diferença é observada no período de fermentação compreendido entre 12 a 48 horas, o que pode estar relacionado à diferença na composição de carboidratos da forragem nas quatro idades. Os valores de FDN e de LIG apresentados na Tab. 2 sugerem que a composição de carboidratos do capim-braquiarão é determinante na sua taxa de fermentação, e ainda que a LIG afeta a fermentação principalmente quando se avalia a ausência de diferença na produção de gases entre as plantas cortadas aos 28 e aos 56 dias. Porém, apesar da menor concentração de FDN do capimbraquiarão cortado aos 28 dias, não houve diferença estatística $(\mathrm{P}>0,05)$ daquele cortado aos 56 dias quanto à produção de gases.
A LIG influência de forma mais determinante a extensão da degradação ruminal e, conseqüentemente, a fermentação dos polissacarídeos (Van Soest, 1994; Hatfield, 1989). As ligninas ligam-se aos componentes da parede celular, tendo a ocorrência desta interação aumentada com a maturidade da forrageira, seja pelo aumento da concentração de LIG e/ou pela modificação na composição dos compostos fenólicos (Jung, 1989; Jung e Allen, 1995).

Na Fig. 1, verifica-se que as taxas de produção de gases (mililitros de gases produzidos/g de MS) em função dos tempos de incubação da forragem cortada aos 28 e aos 56 dias apresentaram comportamento distinto às daquelas cortadas aos 84 e aos 112 dias. No capim-braquiarão cortado aos 28 e aos 56 dias, o pico de produção de gases foi maior entre $18 \mathrm{e}$ 24 horas de incubação, enquanto naquele cortado aos 84 e aos 112 dias o pico de produção de gases foi observado a partir das 36 horas, atingindo seu valor máximo de 48 horas de incubação.

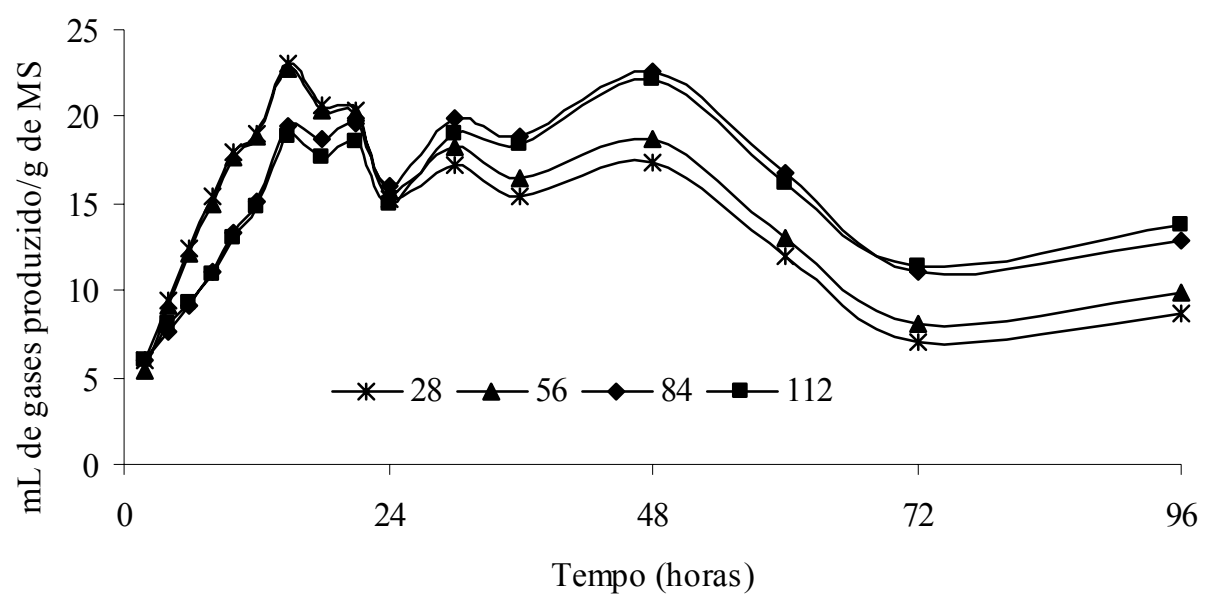

Figura 1. Taxa de produção de gases de Brachiaria brizantha cv. Marandu aos 28, 56, 84 e 112 dias de idade.

A partir desses resultados, pode-se inferir que a forragem cortada aos 28 e aos 56 dias apresentou maior taxa de fermentação no período até 24 horas, e que nas idades de 84 e 112 dias a forrageira mostrou maior fermentabilidade a partir de 36 horas. Essa diferença confirma a suposição citada anteriormente de que a produção acumulada de gases está diretamente relacionada à velocidade de fermentação, sendo essa a função da composição de carboidratos na forragem. Segundo Van Soest (1994), o envelhecimento da forrageira leva ao aumento da parede celular e à diminuição do conteúdo celular na célula vegetal. Concomitantemente, a parede celular apresenta alterações significativas quanto à composição e à estrutura química de 
seus polímeros com o envelhecimento da forragem (Hobson e Stewart, 1997). Essas interações resultariam na fermentação em período mais precoce da forrageira em idade mais jovem e, conseqüentemente, em períodos mais tardios das plantas com maior concentração de parede celular.

As variáveis estimadas pelo modelo proposto por France et al. (1993) e a DIVMS para cada tratamento estão descritas na Tab. 5. Numericamente, os maiores valores de A foram observados na forragem cortada às idades de $56 \mathrm{e}$ 84 dias, enquanto a cortada aos 28 e aos 112 dias apresentou o menor valor. O maior tempo de colonização (L) foi

requerido aos 84 dias, seguido em ordem decrescente pela forragem cortada aos 28 , aos 56 e aos 112 dias, respectivamente. No entanto, tanto $\mu$ como $\mathrm{T} / 2$ descreveram tendência relativa à idade de corte do capim-braquiarão. Observou- se o maior valor de $\mu$ na forragem cortada aos 28 e aos 56 dias, e menor valor no capim cortado aos 84 e aos 112 dias. Já no T/2, observou-se o aumento com o amadurecimento da planta. Estes resultados sugerem que a cinética de fermentação da Brachiaria brizantha cv Marandu apresenta tendência relativa à idade de corte da forrageira, o qual é justificado pela variação observada nos teores de FDN com o avançar da idade da planta, confirmando, dessa forma, as inferências feitas anteriormente. Cone et al. (1999) observaram que, com o aumento da maturidade das plantas, ocorre diminuição na taxa de produção de gases ( $\mu$ ) e na PG, com aumento da $T / 2$; e esses resultados ocorrem em função da diminuição da fermentabilidade da forragem com o aumento da idade. Os resultados encontrados neste estudo referentes ao $\mu$ e ao T/2 confirmam a observação feita por Cone et al. (1999), que sugeriu que o capim-braquiarão tem o potencial de fermentação da matéria seca no rúmen diminuído com o aumento da idade da planta.

Tabela 5. Variáveis da equação de France $^{1}$ para Brachiaria brizantha cv Marandu aos 28, 56, 84 e 112 dias de idade

\begin{tabular}{lcccc}
\hline \multirow{2}{*}{ Variável } & \multicolumn{4}{c}{ Idade ao corte (dias) } \\
\cline { 2 - 5 } & 28 & 56 & 84 & 112 \\
\hline A (ml/g de MS) & 232 & 237 & 237 & 233 \\
L (horas) & $1: 31$ & $1: 25$ & $1: 38$ & $1: 24$ \\
T/2 (horas) & $17: 07$ & $17: 54$ & $21: 34$ & $21: 41$ \\
$\mu$ (hora $^{-1}$ ) & 0,032 & 0,032 & 0,027 & 0,027 \\
\hline
\end{tabular}

${ }^{1}$ France (1993).

A: potencial máximo de produção de gases; L: tempo de colonização; T/2: tempo para produção de $50 \%$ do potencial máximo de produção de gases; $\mu$ : taxa de produção de gases.

No entanto, quando da avaliação da PG, Nogueira et al. (2006b) sugeriram a determinação da DIVMS para que possam ser evitados erros referentes à composição químicobromatológica da forrageira, pois os diferentes substratos, quando fermentados no rúmen, seguem vias metabólicas distintas para a produção de adenosina-trifosfato, resultando em relações variáveis com o volume de gases produzidos (Hobson e Stewart, 1997). Nogueira et al. (2006a) avaliaram substratos originais e lavados quanto à relação entre DIVMS e produção de gases e concluíram que é importante determinar a DIVMS em conjunto com a PG para que se tenha maior confiabilidade. Devido às variações na composição químicabromatológica com a maturidade das plantas forrageiras, Nogueira et al. (2006b) sugeriram a determinação de equações entre a DIVMS e PG para cada idade ao corte da forrageira.

O coeficiente de correlação entre PG e DIVMS foi de 0,98 . Foram obtidas as seguintes equações de regressão: aos 28 dias, DIVMS (\%) =0,288pg$1843\left(\mathrm{r}^{2}=0,97 ; \mathrm{P}<0,001\right)$; aos 56 dias, DIVMS $(\%)=0,285 \mathrm{PG}-0,508\left(\mathrm{r}^{2}=0,96 ; \mathrm{P}<0,001\right)$; aos 84 dias, DIVMS $(\%)=0,283 \mathrm{PG}-5,257 \quad\left(\mathrm{r}^{2}=0,96\right.$; $\mathrm{P}<0,001)$ e aos 112 dias, DIVMS $(\%)=0,306 \mathrm{PG}-$ $9,526\left(\mathrm{r}^{2}=0,95 ; \mathrm{P}<0,001\right)$. Demonstra-se que a variação no volume de gases produzidos refletiu a variação na DIVMS para o capim-braquiarão. Observa-se nos coeficientes bx das equações lineares $(\mathrm{y}=\mathrm{a}+\mathrm{bx})$ para as idades de 28,56 e 84 dias valores muito próximos $(0,288,0,285 \mathrm{e}$ 0,283 , respectivamente), sendo determinado o maior valor de DIVMS pela proximidade de zero do coeficiente "a". Com isso, confirma-se como 
demonstrado anteriormente que o capimbraquiarão cortado aos 56 e 28 dias apresenta maior potencial de digestibilidade e fermentação ruminal.

\section{CONCLUSÕES}

Por meio da técnica in vitro zsemi-automática de produção de gases conclui-se que a melhor época de corte da Brachiaria brizantha cv. Marandu encontra-se entre as idades de 28 e 56 dias, o que proporciona intervalo flexível para uso dessa forrageira.

\section{REFERÊNCIAS BIBLIOGRÁFICAS}

BORGES, A.L.C.C.; RABELO, L.S.; GONCALVES, L.C. et al. Avaliação da Brachiaria brizantha cv Marandu em oito idades de corte em Igarapé - MG. Teores de matéria seca, produção de matéria seca e relação folha/haste. In: REUNIÃO DA SOCIEDADE BRASILEIRA DE ZOOTECNIA, 39. 2002, Recife. Anais...Recife: SBZ, 2002. (CD-ROM)

CONE, J.W.; VAN GELDER, A.H.; DE VISSER, H. et al. Different techniques to study rumen fermentation characteristics of maturing grass and grass silage. J. Dairy Sci., v.62, p.957-966, 1999 .

CORRÊA, L.A.; POTT, E.B. Silagem de capim. In: SIMPÓSIO DE FORRAGICULTURA E PASTAGENS TEMAS EM EVIDÊNCIA. 2001, Lavras. Anais...Lavras: UFLA, 2001. p.339-362.

DIRKSEN, G.; GRÜNDER, H.D.; STÖBER, M. Rosenberger: exame clinico dos bovinos. Rio de janeiro: Guanabara Koogan, 1993. 419p.

FERRARI JÚNIOR, E.; ANDRADE, J.B.; PEDREIRA, J.V.S. et al. Produção e qualidade dos fenos de Brachiaria decumbens e Brachiaria brizantha cv. Marandu sob três freqüências de corte. I. Produção de matéria seca. Bol. Ind. Anim., v.51, p.49-54, 1994.

FRANCE, J.; DHANOA, M.S.; THEODOROU, M.K. et al. A model to interpret gas accumulation profiles associated with in vitro degradation of ruminant feeds. J. Theoret. Biol. v.163, p.99-111, 1993

HATFIELD, R.D. Structural polysaccharides in forages and their degradability. Agric. J., v.81, p.39-49, 1989.

HOBSON, P.N.; STEWART, C.S. The rumen microbial ecosystem. London: Brackie Academic \& Professional, 1997. $719 \mathrm{p}$.

JUNG, H.G. Forage ligninslignin and their effects on fiber digestibility. Agron. J., v.81, p.33-38, 1989.

JUNG, H.G.; ALLEN, M.S. Characteristics of plant cell walls affecting intake and digestibility of forages by ruminants. J. Anim. Sci., v.73, p.2774-2790, 1995.
MAURICIO, R.M.; MOULD, F.L.; DHANOA, M.S. et al. A semi-automated in vitro gas production technique for ruminants feedstuff evaluation. Anim. Feed Sci. Technol., v.79, p.321-330. 1999

MAURÍCIO, R.M.; PEREIRA, L.G.R.; GONÇALVES, L.C. et al. Relação entre pressão e volume para implantação da técnica in vitro semi-automática de produção de gases na avaliação de forrageiras tropicais. Arq. Bras. Med. Vet. Zootec., v.79, p.216-219. 2003.

NOGUEIRA, U.T.; MAURÍCIO, R.M.; GONCCALVES, L.C. et al. Comparação de substratos com diferentes quantidades de carboidratos solúveis utilizando a técnica in vitrof semiautomática de produção de gases. Arq. Bras. Med. Vet. Zootec., v.58, p.633-641, 2006a.

NOGUEIRA, U.T.; MAURÍCIO, R.M.; GONCALVES, L.C. et al. Predição da degradação da material seca pelo volume de gases utilizando a técnica in vitro semi-automática de produção de gases. Arq. Bras. Med. Vet. Zootec., v.58, p.901909, 2006b.

NUNES, S.G.; BOOCK, A.; PENTEADO, M.I.O. Brachiaria brizantha cv Marandu. 2 ed. Campo Grande: EMBRAPACNPGC, 1985. 31p. (Documentos, 21).

OFFICIAL methods of analysis. 13.ed. Washington DC:AOAC, 1980. 1015p.

ØRSKOV, E.R. Trails and trails in livestock research. Abeerden: Garamond, 2002. 204p.

ROSS, G.J.S. Maximum likelihood program (A manual). Hampendon: Tothmsted experimental station, 1987.

SAS/STAT Software:Syntax, Version 6, Cary, NC:SAS Institute Inc., 1993. 151p.

SOARES FILHO, C.V.; RODRIGUES, L.R.A.; PERRI, S.H.V. Produção e valor nutritivo de dez gramíneas forrageiras na região noroeste do estado de São Paulo. Acta Scient., v.24, p.1377-1384, 2002.

THEODOROU, M.K.; WILLIANS, B.A.; DHANOA, M.S. et al. A simple gas production method using pressure transducer to determine the fermentation kinetics of ruminant feeds. Anim. Feed Sci. Technol., v.48, p.185-197, 1994.

VAN SOEST, P.J. Nutritional ecology of the ruminant. 2.ed., Ithaca: Cornell University, 1994. 476p.

VAN SOEST, P.J.; ROBERTSON, J.B.; LEWIS, B.A. Methods for dietary fiber, neutral detergent fiber, and nonstarch polysaccharides in relation to animal nutrition. $J$. Dairy Sci., v.74, p.3583-3597, 1991.

WILLIAMS, B.A. Cumulative gas production: how to measure it, and what it can (not) tell you. In: ISNH6 SATELLITE WORKSHOP/SYMPOSIUM WILD AND DOMESTIC HERBIVORE DIET CHARACTERIZATION, 2003, Mexico. Anais... Mexico: UADY, 2003. p.1-3.

ZIMMER, A.H.; EUCLIDES, V.P.; MACEDO, M.C.M. Manejo de plantas forrageiras do gênero Brachiaria. In: PEIXOTO, A.M.; MOURA, J.C.; FARIA, V.P. Plantas forrageiras de pastagens. Piracicaba: FEALQ, 1995. p.69100. (Serie Atualização em Zootecnia, 13). 